Balancing Shiftwork And Life Outside Work: Do 12-hour Shifts Make A Difference?

\author{
Rebecca Loudoun \\ Department of Employment Relations, \\ Griffith University
}

Rebecca Loudoun

Department of Employment Relations,

Griffith University, Nathan, Brisbane, Australia, 4111

Phone: + 61737357743

Fax: + 61737357177 


\title{
Balancing Shiftwork And Life Outside Work: Do 12-hour Shifts Make A Difference?
}

\begin{abstract}
Twelve-hour shifts are a popular alternative to 8-hour shifts as many consider these shift arrangements superior in terms of facilitating a better social and family life. This view is largely based on anecdotal evidence, however as few studies have examined longitudinal relations between work/non-work conflict and shift length. Using self-report data from 137 machine operators this study examined whether 8- and 12-hour shifts have a differential impact on work/non-work conflict. Relationships between work/nonwork conflict and subjective health were also examined. Profile analysis revealed no significant relationships between shift length and work/non-work conflict. Results of regression analyses indicated that work/non-work conflict was positively related to psychological health on 8 and 12-hour shifts ( $p<$ .01) but not physical health. These results suggest that 12-hour shifts did not offer any benefits or disadvantages for workers trying to reconcile their work and non-work life during the 13-month study period.
\end{abstract}

Key words: shiftwork, work/non-work conflict, 8 vs 12-hour shifts, subjective heath

\section{Introduction}

There is considerable evidence that shiftworkers in general suffer acutely and chronically impaired health (Costa, 2003; Harrington, 2001). There is also growing evidence that they have an increased risk of divorce and children with anxiety and behaviour problems (Pisarski et al., 2006). It is widely accepted that the negative effects of shiftwork arise from the mismatch between altered sleep-wake schedules, internal timing mechanisms, and community rhythms of business, social, recreational, and domestic activity (Costa, 2003). In essence, shiftworkers are required to work and sleep at times that conflict with normal societal and biological patterns. Compounding problems caused by this conflict, external time 
cues such as the light/dark cycle, clock time and the knowledge of others' behaviors encourage shiftworkers to return to normal sleep/wake cycles (Costa, 1998).

A strong argument in favour of 12-hour shifts is that these work arrangements have the potential to eliminate or reduce some of the problems of shiftwork because work is usually compressed into fewer days each week. Thus, workers are generally required to work fewer shifts (therefore fewer night shifts) than they are on 8-hour shifts. This means that there are fewer circadian changes imposed on the body and workers can have more available "free" time with their family and friends (Earle, 2001; Smith, Hammond, Macdonald and Folkard, 1998). Therefore, according to this line of argument, 12-hour shifts can redress some of the conflict shiftworkers tend to report between their work schedule and family, biological and community rhythms.

However, although there are persuasive arguments suggesting that 12-hour shifts are likely to help shiftworkers achieve less work/non-work conflict, relatively few studies have tested this argument empirically. Many studies have linked work/non-work conflict to fatigue, psychological ill-health, depressed mood and increased physical symptoms amongst 8-hour shiftworkers (Bohle and Tilley, 1989; Loudoun and Bohle 1997), but no direct research has examined whether work/non-work conflict changes with the introduction of 12-hour shifts. This study investigates the relationship between work/non-work conflict and shift length using a longitudinal research design, and also examines relationships between work/non-work conflict and physical and psychological health.

\section{Twelve-hour shifts and work/non-work conflict}

Work/non-work conflict is generally defined as occurring when the emotional and behavioral demands of work and non-work roles are incompatible, such that participation in one role is made more difficult by virtue of participation in the other (Carlson, Kacmar, Williams, 2000; Greenhaus and Beutell, 1985). The aspects of non-work life most frequently found to conflict with shiftwork, and the areas where 12-hour shifts may be most beneficial, are domestic activities, social/leisure time, and sleep. 


\subsection{Potential positive effects}

Following an extensive study of the effects of shiftwork on family life, Mott et al., (1965) concluded that shiftwork produced two forms of conflict that have more recently been labeled structural interference and emotional interference (Carlson et al., 2000; Jackson, Zedeck and Summers, 1985). Structural interference arises from the conflicting demands for time at work and family roles. Work and family duties usually cannot be performed simultaneously; a problem that is aggravated by shiftwork because working hours frequently conflict with the most valued times for family activities - weekends and evenings (Knauth and Costa, 1996). Assuming that the length of the working week remains the same, structural interference may be minimized under 12-hour shifts because these arrangements offer more intense periods of non-working hours. The degree of night and weekend work is usually reduced under a two-shift system as the afternoon shift, which most frequently interferes with family time, is generally halved and absorbed into the remaining two shifts. This means that shiftworkers are free most evenings as they are at home when their family finishes school or work (night shifts); they arrive home before the family retires (day shift) or, they are on a non-work day.

As well as interference with family life, shiftwork often restricts social and leisure activities (Knauth, 2001). With an 8-hour roster, workers regularly have to sacrifice leisure time to accommodate domestic chores that are inflexible with respect to timing, such as banking or shopping. A compressed shift schedule may only marginally increase the number of available leisure hours (usually through reduced travel time and preparation for work) but it offers extended periods of leisure time in one block. Also, as workers are usually at work for fewer days each week and they are out of touch with community rhythms less often which may result in them feeling less alienated from their wider community (Presser and Cain, 1983). The extended period of time away from the workplace could also provide individuals with a chance to remove themselves from the job and associated tensions.

Twelve-hour shifts could also alleviate emotional interference, which results from time spent "recovering" from mental fatigue (Carlson et al., 2000) on rest days, and reduces both the quantity and 
quality of family contact time (Jackson et al., 1985). Although it is true that shiftworkers may physically have more time in total to spend with their families than dayworkers (Knauth, 2001) the quality of the interactions may be lessened as the shiftworker is mentally recovering from time spent at work (Tasto, Colligan, Skjei and Polly, 1978).

Emotional interference may be alleviated under 12-hour shifts because workers may be able to use their increased number of days off work to structure their recovery time around their partners', friends' or childrens' schedules. Twelve-hour shiftworkers may also need less time at home recovering if their shift system produces less conflict with sleep (Lowden, Kecklund, Axelsson and Akerstedt, 1996). Impaired or truncated sleep is perhaps the most frequent complaint of shiftworkers on traditional schedules and it is a particular problem on night shift (Akerstedt, 1998; Knauth, 2001). Shiftworkers are more likely to take naps during leisure hours, use days off to catch up on sleep (Winwood, Winefield, and Lushington, 2006), and reduce their sleeping time in an attempt to increase the time spent with their families than day workers (Oginska, Pokorski and Oginska, 1993).

These sleep problems may be minimized under a 12-hour shift system because there are fewer night shifts. The reduction in night shifts is undoubtedly one of the most important potential benefits of 12-hour shifts as there is less disruption to sleep, and less conflict with internal timing mechanisms, both of which are known to cause health problems and fatigue in shiftworkers (Akerstedt 1988; Lowden, et al., 1996). In addition, with fewer rostered working days each week, 12-hour shiftworkers may feel less pressure to reduce sleeping time to increase time spent with their families.

Alongside the potential benefits of 12-hour shifts for work/non-work conflict are potential disadvantages that also need to be considered. Indeed there is increasing concern amongst researchers, workers and various government and union bodies that extended work hours in general and 12-hour shifts in particular produce excessive fatigue and possible risks of accident and injury in the short-term, and deterioration of health and well-being in the long-term (Baker, Heiler and Ferguson, 2003; Pocock, 2001; Rosa, 1995). 


\subsection{Potential Negative Effects}

When looking at conflict between 12-hour shiftwork and non-work life, fatigue is a particular concern, especially for monotonous work and jobs involving a high physical workload. The four extra hours performed on each shift could result in fatigue intensifying throughout the workday and induce decrements in performance and increase accident susceptibility (Rosa, 1995).

Arguments regarding fatigue and 12-hour shifts are even more compelling when the possibility of overtime is considered. While a full 12-hour shift is rarely considered for overtime, there are isolated cases of workers being rostered to work for 18 to 32 hours and requests for workers to cover a portion of a subsequent shift (Bourdouxhe and Toulouse, 2001; Leonard, Fanning, Attwood and Buckley, 1998; Parkes, 1994). There is also evidence indicating a trend towards "flexible work breaks" where rest periods are staggered so that they do not disrupt production. Indeed, some organisations have abolished rest breaks altogether (Heiler, 1996). The combined impact of 12-hour shifts and irregular, or no work breaks, can only increase fatigue.

While some researchers note that increases in fatigue may be offset if the shiftworker has a shorter working week, long blocks of 12-hour shifts (7 - 28 days in a row) are becoming increasingly common in some industries such as remote mining and offshore drilling (Gibbs, Hampton, Morgan and Arendt, 2002; Rodrigues, Fischer and Brito, 2001). Others argue that the larger blocks of time away from work generally afforded by 12-hour shifts are simply used for recovering from the shifts and preparing for the next block of shifts (Kundi et al., 1995), which means that the shiftworker effectively has no more time available for leisure, family or domestic jobs.

In addition, after work, sleep and travel time are accounted for, 12-hour shiftworkers may have less than two hours a day whilst on shift to attend to family duties and prepare for the next workday. This could prove to be an unworkable situation for single parents and families where both parents work. Domestic responsibilities, especially when children are involved, are unlikely to change on a day-to-day basis just because additional hours are performed each shift (Pocock, 2001; Rosa, 1995). In addition, some 
researchers report that 12-hour shifts are harder to swap than 8-hour shifts (Hodgson, 1995), which may compound conflict between work and family life if unexpected commitments arise. Shiftworkers who are committed to regular sporting activities and/or daily training are also likely to be more restricted on workdays involving 12-hour shifts than on workdays involving 8-hour shifts.

From this brief review it is evident that there is considerable equivocal evidence regarding the impact of extended shifts on shiftworkers. Similar conclusions are drawn in extensive reviews of 8-vs 12-hour shifts focusing on a wider selection of variables such as safety and alertness (see for example Smith et al., 1998). There is considerable indirect evidence to suggest that these 12-hour shifts could potentially influence work/non-work conflict, but whether that impact is likely to be positive or negative is unclear. In an effort to gain a more critical picture of the impact of 12-hour shifts on workers, this study examines relationships between shift length, subjective health, and work/non-work conflict.

\subsection{The present study}

The present study used a longitudinal, partly controlled design to examine the relationship between shift length and work/non-work conflict by comparing worker's responses on 8-hour shifts with their responses after 6 and 12 months on 12-hour shifts. This research design was chosen in an attempt to reduce some of the ambiguity about the impact of 12 -hour shifts by providing a more powerful test of causality. It was also chosen in an attempt to shed light on the length of time needed before shiftworkers fully 'experience' a 12-hour roster. With some exceptions (see Di Milia, 1998 and Rosa, 1991) most studies have used cross sectional designs when assessing the impact of 12-hour shifts and those that have been completed have only used two measurement points.

As part of the study, relationships between work/non-work conflict and subjective health were also investigated. Subjective health was included in the variables of interest in the study because the primary premise for examining work/non-work conflict is its established relationship with subjective health amongst workers in general and particularly shiftworkers on 8-hour shifts. Should the results show that there is no relationship between work/non-work conflict and health or that work/non-work conflict ceases 
to be important with 12-hour shifts, then there is little point in reporting the remainder of the study. In this sense, these analyses form the justification for the rest of the study. Based on previous studies, it is anticipated that work/non-work conflict will be positively related to physical and mental health. There is insufficient previous research to hypothesise about the impact of shift length on work/non-work conflict and as such this part of the research is exploratory.

\section{Method}

A longitudinal design was used for the study with data collected from three groups of workers over three time periods. Participants in two of these groups (Groups A and B) changed from 8- to 12-hour shifts during the study while the third group (Group C) acted as a control group for Group A; they performed the same tasks at the same workplace as Group A, but they did not undergo a roster change. All members in the control group were employed on 12-hour shifts several years prior to the study and they stayed on 12-hour shifts throughout the three stages of the study. Participants could not self select their groups and no other workplace changes that were likely to influence the results were introduced during the period of the study.

\subsection{Participants}

A total of 186 machine operators from 2 processing plants volunteered to participate, and 130 males and 7 females (74 per cent) completed the study. All participants were employed full time in similar industries so the broad role and task characteristics of their jobs were the same. The average age of workers was 40 years $(\mathrm{sd}=9.8)$ in Group A $(\mathrm{n}=41) ; 41$ years in Group B $(\mathrm{sd}=9.7 ; \mathrm{n}=79)$; and, 38 years $(\mathrm{sd}=9.2)$ in Group C ( $(n=17)$;. Their average years of experience of shiftwork was $12.2(\mathrm{sd}=8.2)$ in Group A; 17 years in Group B (sd = 10.7); and, $14.1(\mathrm{sd}=8.0)$ in Group C. Twenty-four workers in Group A (41\%); 42 workers in Groups B (53\%); and, 11 workers in the Group C (65\%), had dependent children. Only 5 respondents were single parents. 


\subsection{Measures}

Demographic data were collected on gender, age, number of dependent children, position title, years of experience of shiftwork, and type of roster.

Data on work/non-work conflict and subjective health were collected using three published questionnaires. Perceived conflict between shiftwork and non-work activities was measured using Bohle and Tilley's (1998) version of the work/non-work conflict scale devised bv Shamir (1983). The scale used the following 5 items, assessed on a five-point scale ranging from `completely false' (1) to `completely true' (5): `shiftwork allows me sufficient time for social activities'; `shiftwork does not allow me enough time at home'; 'shiftwork prevents me from participating in sport and leisure activities'; 'my family and close friends complain because shiftwork does not allow me to spend enough time with them'; and 'shiftwork leaves me with enough free time'.

Subjective health was measured using the General Health Questionnaire (GHQ-12; Goldberg, 1972) for psychological symptoms, and the Physical Health Questionnaire (PHQ, Barton, Folkard, Smith, Spelten and Totterdell, 1993) for physical symptoms.

The Likert method was used to score all the scales (see Banks, Clegg, Jackson, Kemp, Stafford and Wall, 1980). Scales were coded so that higher scores indicate increasing psychological strain, physical illhealth or work/non-work conflict.

\subsection{Procedure}

Data were collected in 3 stages over 13 months. At Stage 1 baseline data were collected for groups A and B prior to the introduction of 12-hour shifts (while workers were on 8-hour shifts). One month after the first data collection, these workers changed to 12-hour shifts and data were collected at 6- (Stage 2) and 12-month (Stage 3) intervals after the shift change. For the control group data were collected at the same time periods but no shift change occurred. 


\subsection{Data analysis strategy}

To examine the relationship between work/non-work conflict and physical and mental health under different shift systems, three standard multiple regressions were performed. The first analysis used data collected on 8-hour shifts, while the second and third analyses used data collected after 6 and 12 months respectively on 12-hour shifts. The direction of causal effects was not specified in the analyses so that the unique association of each variable with work/non-work conflict could be isolated.

To examine the relationship between work/non-work conflict and shift length, profile analysis was used as a multivariate alternative to repeated measures analysis of variance (ANOVA). This approach was chosen after initial examination of the data for missing values and violations of the assumptions of regression analysis and ANOVA revealed a violation of the assumption of homogeneity of covariance (Tabachnick and Fidell, 1996). Planned pairwise comparisons between groups within each stage were performed to isolate the possible influence of any extraneous workplace variables.

Analysis of variance (ANOVA) was used to test for differences between the groups on baseline measurements. Results indicated there were no significant differences between the groups and therefore no evidence of pre-existing differences at Stage 1. Independent-samples t-tests also indicated no differences between baseline responses from workers who failed to finish the study and those who did finish.

Owing to the small number of females in the sample, analyses were repeated with and without responses from these participants. However, as no changes were found in the pattern of results or the levels of significance, it was decided to include females in the sample to maximize power in the analyses.

\section{Results}

\subsection{Subjective health}


Regression analysis revealed that work/non-work conflict and psychological health were related on 8hour shifts and after 6 and 12 months on 12-hour shifts (see Table 1). Work/non-work conflict, however, was not significantly related to physical health on 8 - or 12-hour shifts. This result indicates that greater work/non-work conflict was associated with higher mental strain on 8-hour shifts and 12-hour shifts.

\section{Insert Table 1 about here}

\subsection{Work/non-work conflict}

Profile analysis revealed reliable differences between groups when scores were averaged over all stages $\mathrm{F}(2,134)=5.26, \mathrm{p}<.01(\mathrm{y} 2=0.07)$. When averaged over groups, there was no significant effect for stage and there was no interaction between group and stage. Pairwise comparisons between groups revealed significant differences between Group A and Group B at Stages 2 and 3 and between Group A and Group C at Stage 3 (see Table 2). Pairwise comparisons within groups revealed no significant differences for work/non-work conflict over the three stages of the study for any group. These results indicate that work/non-work conflict was not affected by the introduction of 12-hour shifts.

\section{Insert Table 2 about here}

\section{Discussion}

The results of this longitudinal study indicate that shift length did not have a positive or negative effect on work/non-work conflict; responses were not significantly different after 6 or 12 months on 12-hour shifts. Work-non-work conflict was related to psychological symptoms on 8- and 12-hour shifts but it was not related to physical symptoms. These findings have implications for workplaces introducing roster changes without a trial, and for research investigating the impact of 12-hour shifts on health and wellbeing. 
Work/non-work conflict did not vary as a result of shift length. Although there is limited research to compare this result with there is considerable indirect research that sheds light on this finding. The results of this study are in conflict with much of this earlier research, which has found either positive or negative relationships between domestic satisfaction and 12-hour shifts, but rarely no relationship.

For example, Barton Cunningham (1989) found that young married workers without children were more satisfied with their family relations on 12 -hour shifts than they were on 8 -hour shifts. Tucker, Barton and Folkard (1996) also found less social disruption on 12-hour shifts using a male sample working in the chemical industry. Conversely, Thompson (1989) found that an experimental change from 8- to 12-hour shifts amongst female nurses resulted in complaints that the new longer shifts greatly disrupted family life. Similar results are presented by Kundi et al., (1995) (also examining female nurses) and Wallace, Owens and Levens (1990).

There are several possible explanations for differences between the results of this study and those described above. First, it is possible that both groups of literature examined in the beginning of this paper are correct; that is 12-hour shifts could have both a positive and negative impact on work/non-work conflict. Put another way, 12-hour shifts could present different problems to 8-hour shifts and different benefits but when these are taken as a whole they essentially "cancel" each other out. Thus, 12-hour shiftworkers may have different problems but no fewer problems than 8 -hour shiftworkers. This was certainly the view expressed by participants when speaking to the researcher informally, which suggests that it may be an area worthy of investigation.

The makeup of this particular sample may have also influenced the findings. Most studies examining work/non-work conflict in relation to 12 -hour shiftworkers have used predominantly female samples, often with no dependent children (see for example Thompson, 1989; Wallace et al., 1990). There is considerable evidence suggesting that work/non-work conflict is most acute for female shiftworkers as they usually perform an uneven distribution of family and household duties (Leslie, Anderson and Branson, 1991; Robson and Wedderburn, 1990) resulting in diminished sleep length and time spent on 
leisure activities (Oginska, Pokorski, and Oginski 1993). Evidence also suggests that women who have dependent children experience more work/non-work conflict than those who do not (see Loudoun and Bohle, 1997). The predominantly male population in this study (95\%) may have resulted in work/nonwork conflict being less important for these workers irrespective of shift length. The strong relationship with psychological symptoms, however, suggests this was not the case. Results of the study by Tucker et al., (1996), which found that male chemical workers reported less social disruption on 12-hour shifts, also refute this suggestion.

Instead, it is proposed that a superior explanation is differences in the number of workers with dependent children rather than gender. In this study, the majority of workers had dependent children (56\%) whereas previous studies examined workers without children (Barton Cunningham, 1989; Iskra-Golec et al., 1996). There is considerable evidence that 12 -hour shifts can offer social benefits through more free time off in one block (resulting from a compressed working week). People with dependent children, however, cannot alter the daily lives of their children to fit in with their shift schedules (Pocock, 2001; Rosa, 1995). Thus, their day-to-day responsibilities are unlikely to change just because they are on 12-hour shift and, consequently, any benefits from 12-hour shifts offered through more free time in one block could be mitigated by increased difficulties during days on shift.

The final explanation for differences in the present results and those found in previous studies is differences in the research design and the measurement instruments used. With the exception of Barton Cunningham (1989) all of the studies discussed in this section used cross-sectional designs. There is no doubt that longitudinal designs provide a stronger basis from which to infer predictive relationships between variables than cross-sectional surveys. Furthermore, the studies discussed were not designed to examine work/non-work conflict directly. Most of the studies described used a measure of disruption drawn from the Standard Shiftwork Index (Barton et al., 1993), which elicits information on the amount of time available for different social and domestic activities. While these topics are related to work/nonwork conflict they do not directly measure conflict between work and non-work life. 
For example, the longer blocks of free time offered by 12-hour shifts may result in shiftworkers having more time available for social and leisure activities, but it does not necessarily follow that they feel capable of taking advantage of them. While 12-hour shiftworkers may physically have more free time in common with their families than 8-hour shiftworkers, the quality of the interactions may be lower as their time is spent recovering from work (Tasto et al., 1978). Evidence from Kundi et al., (1995) lends support to this argument. They found that 12-hour shifts had a negative effect on leisure and family life and attributed this to the greater recovery needed under 12-hour shifts, which resulted in the erosion of free time during rest breaks.

Although this section of the paper has presented several explanations to explain differences in the pattern of results found in the present study and previous studies, it is important to note that research on the relationship between shift length and work/non-work conflict is rare and consequently this part of the research was largely exploratory. The results need replication with larger sample sizes that allow more systematic analyses. The lack of control group for workers at the second worksite is also a limitation of this study that needs to be considered.

Workers changing to 12-hour shifts were analysed in two separate groups in this study to make the best use possible of the control group and to highlight any confounding worksite variables. Although no differences were found between responses on 8- and 12-hour shifts for both the shift change groups, significant differences were found between groups (and thus between workplaces) once the groups changed to 12-hour shifts. Workers were matched on potential confounding workplace, task and roster variables. However, the sample sizes were uneven and the differences found between groups after the introduction of 12-hour shifts suggest that an unknown workplace variables that occurred at the same time as the shift change, influenced responses. Further research, focusing on a wider range of workplace variables and a larger sample size is needed to shed light on this finding.

Looking at relationships between subjective health and work/non-work conflict, it was anticipated that work/non-work conflict would be related to physical and psychological health on 8- and 12-hour shifts. 
However, although the same pattern of results was found for 8-and 12-hour shifts, work/non-work conflict was only related to psychological health. This result is surprising given the growing body of literature indicating a relationship between work/non-work conflict and diminished subjective health (Bohle and Tilley 1989; Brough and O-Driscoll, 2005; Eby, Casper, Lockwood, Bordeaux and Brinley, 2005; Jackson et al., 1985; Loudoun and Bohle 1997). However, research examining physical symptoms is a recent addition to literature on work/non-work conflict in shiftwork. The few studies completed to date (see Loudoun and Bohle 1997; Bohle and Tilley, 1998) examined shiftworkers on 8-hour shifts in service industries, such as nursing. The present study used machine operators in manufacturing. Workers only performed physical work on rare occasions when maintenance was needed; their duties predominantly involved monitoring equipment. This pattern of work tasks contrasts with nurses who are frequently on their feet and interacting with others. As a result, the manufacturing sample in this study may have needed less recovery time at home.

In the absence of a comparison group performing more active work, this suggestion is largely speculative. It does, however, provide one explanation for the non-significant relationship between work/non-work conflict and psychological health in the presence of a strong relationship with psychological health. It is also relevant to note that this aspect of the research did not capitalise on the longitudinal aspect of the research design as subjective health was a secondary variable of interest in the study and it was not possible to manipulate these variables within the greater aims of the study. Future research designed to focus more narrowly on these variables is needed to draw firm conclusions about subjective health, shift length and work/non-work conflict. The only firm conclusion that can be drawn from these data is work/non-work conflict is important for psychological health amongst workers performing sedentary work tasks. This result provides further evidence to support previous research. In particular it replicates the finding reported by Loudoun and Bohle (1997) in relation to nurses on 8-hour shifts and indicates that the relationship is generalisable to a predominantly male sample in manufacturing on 8 - and 12-hour shifts. 
In summary this study indicates that 12-hour shifts did not deliver the benefits anticipated by many workers and encouraged by some advocates of 12-hour shifts in terms of work/non-work conflict. At the same time the findings indicate that 12-hour shifts were no worse for work/non-work conflict, although it is important to note that comparisons in this study were made relative to 8-hour shifts, which are known to have a detrimental impact on work/non-work conflict. The study supports previous research highlighting the importance of work/non-work conflict for shiftworkers' mental health but it found that work/non-work conflict did not influence physical health for a predominantly male population. The study failed to find evidence of an initial change in work/non-work conflict after 6 months, which suggests that workers were not influenced by aspects of the change process outside the extension in shift length or they were able to differentiate these changes from the roster trial. These findings have important implications for workplaces introducing roster changes and for research investigating the impact of 12-hour shifts on workers. They suggest that relationships between shift length, work/non-work conflict and subjective health are more complex than acknowledged by researchers. They also suggest that interventions of less than 12 months are adequate to assess the suitability of a roster. In combination the study provides sound empirical evidence to assist with designing roster intervention studies and to assess the impact that 12hour shifts are likely to have for workers trying to reconcile their work and non-work lives.

\section{References}

Akerstedt, T., Knutsson, A., 1986. Shift work, disease and epidemiology, in Haider, M., Koller, M., Cervinka, R. (Eds.), Night and shiftwork: Longterm effects and their prevention. Peter Lang, Frankfurt am Main.

Akerstedt, T., 1988. Sleepiness as a consequence of shiftwork. Sleep. 11 (1), 17-34.

Akerstedt, T., 1998. Shift work and disturbed sleep/wakefulness. Sleep Medicine Reviews (2). 117-128.

Baker, A., Heiler, K., Ferguson, S., 2003. The impact of roster changes on absenteeism and incident frequency in an Australian coal mine. Occupational and Environmental Medicine. 60, 43-49. 
Banks, M. H., Clegg, C. W., Jackson, P. R., Kemp, N. J., Stafford, E. M., Wall, T. D. 1980. The use of the General Health Questionnaire as an indicator of mental health in occupational studies. Journal of Occupational Psychology, 53, 187-194.

Barton Cunningham, J., 1989. A compressed shift schedule: Dealing with some of the problems of shiftwork. Journal of Organizational Behavior. 10, 231-235.

Barton, J., Folkard, S., Smith, L.R., Spelten, E.R., Totterdell, P.A., 1993. Standard Shiftwork Index Manual. The University of Sheffield, Sheffield.

Bohle, P., Tilley, A., 1989. The impact of nightwork on psychological well-being. Ergonomics. 32, 10891099.

Bohle, P., Tilley, A. J. 1998. Early experience of shiftwork: Influences on attitudes. Journal of Occupational and Organizational Psychology, 71, 61-79.

Bond, J., Galiski, E., Swanberg, I., 1998. The 1997 national study of the changing workplace. Families and Work Initiative, New York.

Bourdouxhe, M., Toulouse, G., 2001. Health and safety among film technicians working extended shifts. Journal of Human Ergology. 30, (1/2), 113-118.

Brough, P., O’Driscoll, M. 2005. Work-family conflict and stress. In A.S.G. Antoniou and C. L. Cooper (Eds.), Research Companion to Organizational Health Psychology (pp. 346-365). Cheltenham, UK: Edward Elgar.

Carlson, D. S., Kacmar, K. M., Williams, L. J.2000. Construction and validation of a multidimensional measure of time-based work-family conflict. Journal of

Vocational Behaviour, 56, 249-276.

Costa, G. 2003. Shiftwork and occupational medicine: An overview. Occupational Medicine, 53(2) 8388.

Costa, G., 1998. Guidelines for the medical surveillance of shift workers. Scandinavian Journal of Work. Environment and Health. 24 (Suppl. 3), 151-156. 
Dalakas, M.C., Mock, V., Hawkins, M.J., 1998. Fatigue: definitions, mechanisms, and paradigms for study. Seminars in Oncology. 25, 48-53.

Di Milia, L. 1998. A longitudinal study of the compressed workweek: Comparing sleep on a weekly rotating 8-h shift system to a faster rotating 12-h system. International Journal of Industrial Ergonomics. 21, 199-207.

Earle, J., 2001. Managing the social cost of shiftwork on the employee's family and social environment. Paper presented at the Best Practice Rostering and Shiftwork Conference, Sydney.

Eby, L. T., Casper, W. J., Lockwood, A., Bordeaux, C., Brinley, A. 2005. Work and family research in IO/OB: Content analysis and review of the literature (1980- 2002). Journal of Vocational Behavior, 66, 124-197.

Gibbs, M., Hampton, S., Morgan, L., Arendt, J., 2002. Adaptation of the circadian rhythm of 6sulphatoxymelatonin to a shift schedule of 7 nights followed by 7 days in offshore oil rig workers. Neuroscience Letters. 325, 91-94.

Goldberg, D. P., 1972. The detection of psychiatric illness by questionnaire. Oxford University Press, Oxford.

Greenhaus, J.H., Beutell, N.J., 1985. Sources of conflict between work and family roles. Academy of Management Review. 10, 76-88.

Harrington, JM. 2001. Health effects of shift work and extended hours of work. Journal of Occupational and Environmental Medicine, 58: 68-72.

Heiler, K., 1996. Is Enterprise Bargaining Good for Your Health? ACIRRT, Sydney, Australia.

Hodgson, L.A., 1995. Nurses working 12-hour shifts in the hospice setting. Palliative Medicine. 9 (2), 153-163.

Iskra-Golec, I., Folkard, S., Marek, T., Noworal, C., 1996. Health, well-being and burnout of ICU nurses on 12 and 8 hour shifts. Work and Stress. 10, 251-256. 
Jackson, S. E., Zedeck, S., Summers, E., 1985. Family life disruptions: Effects of job-induced and emotional interference. Academy of Management Journal. 28 (3), 574-586.

Knauth, P., 2001. Strategies for the implementation of new shift systems. Journal of Human Ergology. 30, 9-14.

Knauth, P., and Costa, G., 1996. Psychosocial effects, in Colquhoun, W.P., Costa, G., Folkard, S., Knauth, P. (Eds.) Shiftwork: Problems and solutions. Peter Lang, Frankfurt, pp. 89-112.

Kundi, M., Koller, M., Stefan, H., Lehner, L., Kaindlsdorfer, S., Rottenbucher, S., 1995. Attitudes of nurses towards 8-h and 12-h shift systems. Work and Stress. 9, 134-139.

Leonard, C., Fanning, N., Attwood, J., Buckley, M., 1998. The Effect of fatigue, sleep deprivation and onerous working hours on the physical and mental wellbeing of pre-registration house officers. Israel Journal of Medical Science. 167, 21-25.

Leslie, L.A., Anderson, E.A., Branson, M.P., 1991. Responsibility for children: The role of gender and employment. Journal of Family Issues. 12 (2), 197-210.

Loudoun, R.J., Bohle, P.L., 1997. Work/non-work conflict and health in shiftwork: Relationship with marital status and social support. International Journal of Occupational and Environmental Health. 3 (Suppl. 2), S71-S77.

Lowden A, Kecklund G, Axelsson J, Åkerstedt, T., 1996. Changing from 8 to 12-Hour Shift. Stress Research Reports No 269, Stockholm 1996. ISSN 0280-2783.

Mott, P.E., Mann, F.C., McLoughlin, Q., Warwick, D.P., 1965. Shift work: The social, psychological and physical consequences, University of Michigan Press, Ann Arbour.

Oginska, H., Pokorski, J., Oginski, A., 1993. Gender, ageing and shiftwork intolerance. Ergonomics. 36 (1-3), 161-168.

Parkes, K., 1994. Sleep patterns, shiftwork and individual differences: A comparison of onshore and offshore control room operators. Ergonomics. 37, 827-844.

Pisarski, A., Brook, C., Bohle, P., Gallois, C., Watson, B., Winch, S.2006. Extending a model of shiftwork tolerance. Chronobiology International, 23(6), 1363-1377. 
Pocock, B., 2001. The Effects of Long Hours on Family and Community Life, Queensland Department of Industrial Relations, Brisbane, Australia.

Presser, H.B., Cain, V.S., 1983. Shiftwork among dual earner couples with children. Science. 219, 876879.

Robson, M., Wedderburn, A., 1990. Women's shiftwork and their domestic commitments, in Costa, G.

Cesana, G. Kogi, K., Wedderburn, A. (Eds.), Shiftwork: Health, sleep and performance. Peter Lang, Frankfurt am Main, pp. 137-142.

Rodrigues, V.F., Fischer, M.F., Brito, M.J., 2003. Shiftwork at a modern offshore drilling rig. Journal of Human Ergology. 30, (1/2), 167 - 172.

Rosa, R. R. 1991. Performance, alertness and sleep after 3.5 years of 12-hour shifts: A follow up study. Work and Stress. 5, 107-116.

Rosa, R.R., 1995. Extended workshifts and excessive fatigue. Journal of Sleep Research. 4 (Suppl. 2), 5156.

Shamir, B., 1983. Some antecedents of work/nonwork conflict. Journal of Vocational Behavior. 23, 98111.

Shen, J., Botly, L. C. P., Chung, S. A., Gibbs, A. L., Sabanadzovic, S., Shapiro, C. M. 2006. Fatigue and shift work. Journal of Sleep Research, 15(1), 1-5.

Smith, L., Hammond, T., Macdonald, I., Folkard, S., 1998. 12-hour shifts are popular but are they a solution? International Journal of Industrial Ergonomics. 21, 323-331.

Tabachnick, B.G., Fidell, L.S., 1996. Using multivariate statistics. Harper and Row, New York.

Tasto, D.L., Colligan, M.J., Skjei, E.W., Polly, S.J., 1978. Health consequences of shiftwork (SRI Project URU-4426). Department of Health, Education and Welfare, Washington.

Thompson, J., 1989. Rigour round the clock. Nursing Times. 85, 21.

Tucker, P., Barton, J., Folkard, S., 1996. Comparison of eight and 12 hour shifts: impacts on health, wellbeing, and alertness during the shift. Occupational and Environmental Medicine. 53 (11), 767-72. 
Wallace, M., Owens, W., Levens, M., 1990. Adaptation to twelve hour shifts, in Wiersma, U.J., Van Den Berg, P., 1991. Work-home role conflict and domestic responsibilities among men and women in dual earner families. Journal of Applied Social Psychology. 21 (15), 1207-1217.

Winwood, PC., Winefield, A H., Lushington, K. 2006. Work-related fatigue and recovery: the contribution of age, domestic responsibilities and shiftwork. Journal of Advanced Nursing, 56(4), 438449. 